\title{
Estimation of high risk pregnancy contributing to perinatal morbidity and mortality from a birth population-based regional survey in 2010 in China
}

Libo Sun ${ }^{1 \dagger}$, Hongni Yue ${ }^{2+}$, Bo Sun ${ }^{1 *}$, Liangrong Han², Zhaofang Tian ${ }^{3}$, Meihua Qi ${ }^{2}$, Shuyan Lü ${ }^{3}$, Chunming Shan ${ }^{4}$, Jianxin Luo ${ }^{4}$, Yujing Fan ${ }^{5}$, Shouzhong Li $i^{5}$, Maotian Dong ${ }^{6}$, Xiaofeng Zuo ${ }^{7}$, Yixing Zhang ${ }^{8}$, Wenlong Lin ${ }^{9}$, Jinzhong $X u^{10}$, Yongbo Heng ${ }^{11}$ and Huai'an Perinatal-Neonatal Study Group

\begin{abstract}
Background: Neonatal mortality reduction in China over past two decades was reported from nationwide sampling surveys, however, how high risk pregnancy affected neonatal outcome is unknown. The objective of this study was to explore relations of pregnancy complications and neonatal outcomes from a regional birth population.

Methods: In a prospective, cross-sectional survey of complete birth population-based data file from 151 level I-III hospitals in Huai'an region in 2010, pregnancy complications were analyzed for perinatal morbidity and mortality in association with maternal and perinatal characteristics, hospital levels, mode of delivery, newborn birth weight and gestational age, using international definition for birth registry and morbidities.

Results: Pregnancy complications were found in 10\% of all births, in which more than $70 \%$ were delivered at level II and III hospitals associated with higher proportions of fetal and neonatal death, preterm birth, death at delivery and congenital anomalies. High Cesarean section delivery was associated with higher pregnancy complications, and more neonatal critical illnesses. The pregnancy complications related perinatal morbidity and mortality in level III were 2-4 times as high as in level I and II hospitals. By uni- and multi-variate regression analysis, impact of pregnancy complications was along with congenital anomalies and preterm birth, and maternal child-bearing age and school education years contributing to the prevalence.
\end{abstract}

Conclusions: This survey revealed variable links of pregnancy complications to perinatal outcome in association with very high Cesarean section deliveries, which warrants investigation for causal relations between high risk pregnancy and neonatal outcome in this emerging region.

Keywords: Morbidity, Mortality, Perinatology, Perinatal risks, Neonatal outcomes, High-risk pregnancy

\section{Background}

In the past decade there has been a dramatic decline in mortality of children under 5 years old in China, from $60 / 1,000$ in early 1990 to a level below $15 / 1,000$ live births in 2012 as recently reported by the National Health and Family Planning Commission (www.nhfpc.gov.cn, 2013 July), in great extent associated with the reduction of

\footnotetext{
* Correspondence: bsun98@aliyun.com

${ }^{\dagger}$ Equal contributors

'Departments of Pediatrics and Neonatology, Children's Hospital and the Institutes of Biomedical Science, Fudan University, and the Laboratory of Neonatal Medicine, National Health and Family Planning Commission, Shanghai 201102, China

Full list of author information is available at the end of the article
}

neonatal mortality [1-8], i.e., from $40 / 1,000$ to $<7 / 1,000$ live births, along with significantly reduced maternal death rate $(<25 / 100,000$ births $)$ and narrowed disparities between rural and urban death rates. This was mainly due to effective implementation of prenatal care from early pregnancy, hospital delivery, delivery room resuscitation and neonatal special care, and medications for infectious diseases, diarrhea and malnutrition, among others [7-13]. Although national vital statistics revealed this trend, it is not known yet on how the high risk pregnancy would link to perinatal and neonatal death rate in total births and live births. As there are great variations in different regions in China, and perinatal and neonatal 
mortality contributed to the under five children's mortality by $60-70 \%$, how to improve the perinatal and neonatal survival is a big challenge not only for the health care givers and clinical technology, but also public health care administrators and practitioners, policy makers, and child welfare, special care and education professionals in the whole society and local communities. A variety of questions are raised from potential burden in technologies and resource to ethics regarding limit of viability, where lacking of systematic information and reporting, diagnostic means and care standard, resources of public health care system, and staff competence and availability at community level, etc., are commonly encountered but compelling to find solutions for sustainability in the current development in developing countries.

There is no complete birth-population-based regional or provincial data of survey available so far regarding high risk pregnancy contributing to the perinatal and neonatal morbidity and mortality. Existing information come mostly from surveys based on the approaches by sampling of selected level II hospitals of rural counties and urban districts for total births and related death causes, which provided estimated nation-wide data $[7,8]$, but may not provide perinatally associated maternal-fetal and neonatal disease incidence and death rate from different hospital level based information, neither is valid for estimation of nation-wide perinatal and neonatal morbidity and mortality appropriate to the need of country's development. Besides, in the nation-wide reporting system for regional vital statistics, the births earlier than 29 weeks of gestational age (GA) are not included whereas advanced neonatal special care at regional and county/city hospitals is common now in many emerging regions for neonates born before 29 weeks of GA or $<1,000 \mathrm{~g}$ of birth weight (BW) to survive. Therefore, it does not provide perinatal and neonatal information associated with pregnant status and complications, or incidence, management and outcome (death and complications) of specific maternal-fetal and neonatal disorders. Neither does it provide information of how many deaths are related to inappropriate coverage of prenatal care in regions with different levels of health care service. Thus, listing of neonatal death rate and their causes only has shown a trend of changes in neonatal death and underlying causes, but lacks comprehensive view as to what extent the obstetric and neonatal clinic performance as well as regional public health policy and resource really contribute to the overall and specific neonatal outcome. Considering the high birth population and dramatic improvement of perinatal and neonatal care in many emerging regions of the country, an in-depth study of high risk pregnancy and prenatal morbidity related fetal and neonatal outcome is compelling. In this regard, we prospectively conducted a regional complete birth population-based, cross-sectional survey in combination with most, if not all, of the hospitalized high risk pregnancies and neonates with various diseases, which provides information including high risk pregnancy contributing to the perinatal-neonatal morbidity and mortality using epidemiological methodology in Huaian [14], Jiangsu province, China.

The objective of this analysis from the cross-sectional survey-based descriptive data was to delineate high risk pregnancy linking to the fetal and neonatal morbidity and mortality. Characterizing the incidence of prenatal and intrapartum complications, mode of delivery associated perinatal and neonatal risks and outcomes from regional hospitals may facilitate an estimation of nation-wide pregnancy and childbirth related efficacy of policies, strategies and programs as well as burden and resource limitation, for understanding the trend and perspectives of woman and child health care development in China.

\section{Methods}

\section{Summary of study region and population}

The survey was conducted in Huai'an city, a prefectural region, Jiangsu province, located in the eastern part of China with a population of 5,400,000 and nearly 60,000 births in 2009, with approximately $5 \%$ migrant people for seasonal, economic living in this region. There were almost equal proportion of residents from both urban and rural origin, and economic levels, judged by gross domestic production per head, were similar to that of the national averages in 2010. Its socio-cultural tradition was also representative of average in most of the east and midland provinces of the country. We assumed that a cross-sectional, perinatal-neonatal survey in Huai'an region should represent the situation in most emerging regions of China, with intermediate development in both economics and woman and child health care, presumably accounting for up to $50 \%$ of the total Chinese population (1.34 billion in 2010 census), as characterized by high hospital delivery (>99\%), health insurance for most rural residents $(>95 \%)$ and health care infrastructure for coverage and availability.

\section{Synopsis of the study protocol}

Details of the collaborative study group for perinatalneonatal care in Huaian region, data collection and quality control was reported elsewhere [14], and are summarized below:

Study setting: 151 level I-III hospitals (Table 1) providing child delivery and neonatal care service (level II-III hospitals).

Study design: prospective, cross-sectional survey of complete birth data from hospital deliveries including pregnancy complications and perinatal morbidities. 
Table 1 Comparison of all child births and related morbidity and mortality in different levels of hospitals in Huai'an

\begin{tabular}{|c|c|c|c|c|}
\hline Hospital level & 1 & II & III & $\mathbf{P}$ \\
\hline Number of hospitals & 129 & 15 & 7 & \\
\hline All births & $31,680(52.3)$ & $19,767(32.6)$ & $9,168(15.1)$ & \\
\hline Fetal deaths/stillbirth & $36(0.1)$ & $143(0.7)$ & $71(0.8)$ & \\
\hline Live births & $31,644(99.9)$ & $19,624(99.3)$ & $9,097(99.2)$ & \\
\hline Males & $16,900(53.5)$ & $10,539(53.5)$ & $4,967(55.1)$ & 0.018 \\
\hline Gestational age (weeks) & $39.9 \pm 1.2$ & $39.6 \pm 1.5$ & $39.0 \pm 2.1$ & $<0.001$ \\
\hline Birthweight (grams) & $3,469 \pm 447$ & $3,443 \pm 495$ & $3,338 \pm 604$ & $<0.001$ \\
\hline Preterm births & $404(1.3)$ & 776 (3.9) & $1,059(11.6)$ & $<0.001$ \\
\hline Low birthweight & $395(1.2)$ & $545(2.8)$ & $751(8.3)$ & $<0.001$ \\
\hline Multiple-births & $300(0.9)$ & $385(1.9)$ & $403(4.4)$ & $<0.001$ \\
\hline Congenital anomalies & $117(0.4)$ & $119(0.6)$ & $78(0.9)$ & $<0.001$ \\
\hline Cesarean section & $15,566(49.2)$ & $11,155(56.6)$ & $5,243(57.5)$ & $<0.001$ \\
\hline Pregnancy complications & $1,766(5.6)$ & 2,380 (12.1) & $1,905(21.1)$ & $<0.001$ \\
\hline Hypertension & $327(1.0)$ & $410(2.1)$ & $279(3.0)$ & $<0.001$ \\
\hline PROM & $1,062(3.3)$ & $1,211(6.1)$ & $1,017(11.1)$ & $<0.001$ \\
\hline Anemia & $236(0.7)$ & $363(1.8)$ & $147(1.6)$ & $<0.001$ \\
\hline Maternal age (years) & $25.5 \pm 5.2$ & $26.1 \pm 5.1$ & $26.7 \pm 4.9$ & $<0.001$ \\
\hline Delayed childbearing & $2,543(8.1)$ & 1,698 (8.6) & $824(9.0)$ & 0.006 \\
\hline$>9$ years' education & $2,223(7.4)$ & 4,261 (23.2) & $3,855(50.0)$ & $<0.001$ \\
\hline Amniotic fluid volume & & & & $<0.001$ \\
\hline Normal & $29,162(93.4)$ & $18,037(92.2)$ & $7,665(90.6)$ & \\
\hline Polyhydramnios & $192(0.6)$ & $134(0.7)$ & $150(1.8)$ & \\
\hline Oligohydramnios & $1,873(6.0)$ & $1,400(7.2)$ & $647(7.6)$ & \\
\hline Amniotic contamination & & & & $<0.001$ \\
\hline Normal & $27,647(87.5)$ & $16,240(82.5)$ & $7,639(86.8)$ & \\
\hline Grade I & $1,845(5.8)$ & $1,105(5.6)$ & $286(3.2)$ & \\
\hline Grade II & $1,356(4.3)$ & $1,069(5.4)$ & $324(3.7)$ & \\
\hline Grade III & $732(2.3)$ & $1260(6.4)$ & $548(6.2)$ & \\
\hline \multicolumn{5}{|l|}{ Apgar score } \\
\hline $1-\min \leq 7$ & $783(2.5)$ & 767 (3.9) & $740(8.2)$ & $<0.001$ \\
\hline $1-\min \leq 3$ & $75(0.2)$ & $176(0.9)$ & $98(1.1)$ & $<0.001$ \\
\hline $5-\min \leq 7$ & $105(0.3)$ & $193(1.0)$ & $244(2.7)$ & $<0.001$ \\
\hline $5-\min \leq 3$ & $35(0.1)$ & $137(0.7)$ & $64(0.7)$ & $<0.001$ \\
\hline Deaths $^{a}$ & $56(0.2)$ & $156(0.8)$ & $90(1.0)$ & $<0.001$ \\
\hline
\end{tabular}

All values are given in numbers and percentage (\% of all births in each hospital level category) or means \pm SD. Definition of abbreviations: PROM, premature rupture of membrane.

aIncluding fetal deaths/stillbirth and neonatal deaths immediately at delivery but counted as live births.

Study population: all births including fetal death, stillbirth and live births collected from Jan 1 to Dec 31, 2010.

Sample size: based on 2009 total births number, it is estimated to be 60,000-61,000 from hospital deliveries in the whole year 2010.

Data collection: for all the hospital deliveries, each birth should have a case record form to be collected through regional perinatal-neonatal information network system, and assisted by co-investigators and task force group members from most level II and III hospital obstetric and pediatric departments and outreaching local (county and district) level I hospitals and clinic services.

Study variables: maternal, fetal and neonatal biological and clinical pathological variables on prenatal, intrapartum, and postnatal examinations, interventions and outcome. 
The study protocol was approved by the Ethics Committee and Scientific Committee of the Children's Hospital of Fudan University, and adopted by all the participating hospitals through local scientific committee approval according to Chinese regulation for clinical investigation. As data were collected from observational parameters and no specific intervention was used in the protocol, informed consent was waived.

\section{Definitions of vital statistics and perinatal morbidities}

Live birth, fetal death or stillbirth, and death during delivery are defined according to the $10^{\text {th }}$ revision of the international classification of diseases $[15,16]$, and details of birth related definitions such as GA, BW and perinatal and neonatal death rate are described elsewhere [14]. The perinatal period commences at 22 complete weeks (154 days) of GA, ended at 7 postnatal days and the neonatal period is the first 28 complete days after birth. Fetal death is synonymous of stillbirth. The fetal status, perinatal morbidities, birth defects (BD) or congenital anomalies, and major neonatal diseases are defined according to Fanaroff and Martin [17] and domestic clinical criteria. The same applies for diagnosis of pregnancy complications as obstetric pathologies of each pregnancy based on both domestic criteria adopting internationally recognized definitions [16], and presented as incidence rates using numbers of total births as denominator. Incidence of specific neonatal disease is expressed by using either total live births as denominator or total hospitalized numbers as constitutive rate where appropriate [14].

\section{Quality control}

To ensure that all the records to be accurate and complete, on-site physician/investigator and coordinators cross checked all the variables and values, along with visiting, telephone or e-mail communication, for verification and correction of the data. General quality control inspections were also provided for birth registration or medical records from all the municipal and county hospitals, and 20\% township hospitals [14]. Educational sessions were provided to ensure clinical diagnosis and management conforming to the best available domestic criteria to each level of clinical service and capacity.

\section{Statistical analysis}

The EPIDATA database was used for datasheet recordings and statistical analysis was performed using SPSS software (v. 16.0, SPSS Inc. Chicago, IL). Numerical data were presented by the mean (standard deviation, SD) or median (interquartile range, IQR) where appropriate, using one way analysis of variance for comparisons of continuous variables between subset data. Categorical variables were represented as frequencies or rates, using
Chi square test for comparison of differences. A p value $<0.05$ was considered statistically significant. Missing data for each variable in the analysis ranged in $0.2-0.8 \%$ and were considered acceptable. For assessment of relative risks of perinatal mortality associated with pregnancy complications, perinatal morbidities and neonatal status at birth, uni- and multi-variate logistic regression analysis was performed for clinical variables. Results are reported as odds ratio (OR) or relative risk and 95\% confidence interval (CI).

\section{Results}

\section{General conditions of total births and live births}

Table 1 illustrates that all birth related maternal-fetal and neonatal data, as well as birth delivery related morbidities in three levels of the hospitals, and that $85 \%$ deliveries were from level I and II hospitals. It also demonstrates that more preterm birth with low BW, pregnancy complications, congenital anomalies, Apgar score $\leq 3$ at 1-min and 5-min, high risk newborns, and neonatal deaths at delivery were seen at level II and III hospitals, suggesting centralized management of high risk pregnancy and delivery in the region.

Over the 12-month study period, there were totally 61,227 birth registries, with $99.6 \%(60,986)$ as live birth in which 60,615 had birth information collected (99\% of the total births). The total birth rate was $11.3 \%$ (referenced to $5,400,000)$. There were $32,406(53.8 \%)$ males and 27,874 females in the total births, or a male-to-female ratio of 116:100. This ratio was even higher with increasing $\mathrm{BW}$ strata or order of the births [14]. The information of GA and BW related general and stratified data and analysis are reported elsewhere [14]. Incidence of BD was found in $0.67 \%(411 / 60,986)$ including $88(21.4 \%)$ cleft lip and palate, 53 (12.9\%) finger or toe malformations, 47 (11.4\%) congenital heart disease (CHD), 35 (8.5\%) neural tube defects, 31 (7.5\%) urogenital system malformations, 25 (6.1\%) external ear malformations, 19 (4.6\%) hydrocephalus, 19 (4.6\%) alimentary system malformations, among others. The BD rate decreased with increasing BW, male being $0.73 \%$ and female $0.62 \%(\mathrm{p}=0.114)$, respectively.

\section{Pregnancy complications}

Overall $10 \%(6,051 / 60,445)$ deliveries had significantly pregnancy complications as major risk factors such as premature rupture of membrane $(3,290,5.4 \%)$, hypertension $(1,016,1.7 \%)$, anemia $(746,1.2 \%)$, preeclampsia (277, $0.4 \%$ ), placenta previa (181), hepatitis (174), infection (107), diabetes (85), cardiac diseases (82), placenta abruption (80), renal diseases (16), among others. Table 2 shows, from all the deliveries, maternal and perinatal status with and without major pregnancy complications. Prevalence of Cesarean (C)-section, proportions of fetal death/ stillbirth, preterm birth, low birth weight, multiple births, 
Table 2 Pregnancy complication related maternal and fetal birth status

\begin{tabular}{|c|c|c|c|}
\hline Pregnancy complications & Yes & No & $P$ values \\
\hline All pregnancies & $5,938(10.0)$ & $53,925(90.0)$ & \\
\hline Maternal age (years) & $26.7 \pm 5.6$ & $25.8 \pm 5.1$ & $<0.001$ \\
\hline$<20$ & $136(2.3)$ & $1,348(2.5)$ & \\
\hline $20-24$ & $2,483(42.0)$ & $26,168(48.8)$ & \\
\hline $25-29$ & $1,872(31.7)$ & $15,566(29.0)$ & \\
\hline $30-34$ & $712(12.0)$ & $6,228(11.6)$ & \\
\hline$\geq 35$ & 706 (11.9) & $4,296(8.0)$ & \\
\hline First delivery & $4,093(68.0)$ & $34,921(64.7)$ & $<0.001$ \\
\hline Cesarean section & $4,315(71.6)$ & $27,553(50.8)$ & $<0.001$ \\
\hline Fetal deaths/stillbirths & $34(0.6)$ & $155(0.3)$ & $<0.001$ \\
\hline Birth numbers & $6,051(10.0)$ & $54,394(90.0)$ & \\
\hline Live births & $6,017(99.4)$ & $54,239(99.7)$ & \\
\hline Preterm births & $860(14.2)$ & $1,370(2.5)$ & $<0.001$ \\
\hline 32-36 weeks & $759(12.6)$ & $1,174(2.2)$ & \\
\hline 28-31 weeks & $96(1.6)$ & $170(0.3)$ & \\
\hline 24-27 weeks & 5 & 26 & \\
\hline Post-term births & $90(1.5)$ & $1602(3.0)$ & $<0.001$ \\
\hline Low birthweight & $541(9.0)$ & $1140(2.1)$ & $<0.001$ \\
\hline Multiple-births & $224(3.7)$ & $859(1.6)$ & $<0.001$ \\
\hline Congenital anomalies & $56(0.9)$ & $257(0.5)$ & $<0.001$ \\
\hline Deaths ${ }^{\mathrm{a}}$ & $54(0.9)$ & $194(0.4)$ & $<0.001$ \\
\hline
\end{tabular}

All values are given in numbers and percentage (\% of all pregnancies or birth

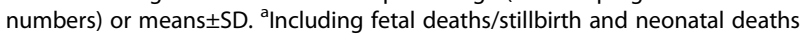
immediately at delivery but counted as live births.

congenital anomalies (BD), death at delivery, and neonatal death were significantly higher in those with pregnancy complications than those without. Tables 3 and 4 illustrate neonatal BW and GA strata associated pregnancy complications, birth related death rate, gender, neonatal morbidity and mortality. With increasing BW, more males and C-section deliveries were getting higher whereas preterm births, multiple births, congenital anomalies, pregnancy complications, hospitalized infants, oxygen therapy, mechanical ventilation, corticosteroid use, and major morbidities were getting lower. The same trend was true with increasing GA.

Table 5 demonstrates mode of delivery related perinatal status and complications. In those by vaginal delivery, there was $0.7 \%$ as dystocia requiring assisted operational procedures. There was difference of $\mathrm{C}$-section rate between those whose BW was $<2,500$ or $\geq 2500 \mathrm{~g}(47.1 \%$ vs. 53.1\%, $\mathrm{P}<0.001)$. The $\mathrm{C}$-section rate for those with pregnancy complications was significantly higher (Table 2). More neonates from C-section had history of abnormal amniotic fluid quantity, CHD and respiratory distress syndrome, required oxygen therapy and mechanical ventilation in contrast to fewer jaundice and cephalohematoma than those from vaginal delivery. From Table 6, more pregnancy complications, preterm births and low BW rates, and congenital anomalies (BD) were seen in those whose maternal age $>35$ years old. In those whose age $<20$ years old, there were also high proportions of preterm births and low BW rates. The average maternal age was $25.9 \pm 5.1$ (median 24, range 16-49) years old, and $2.47 \%(1,490 / 60,209)$ were $<20$ years old. Delayed child-bearing ( $\geq 35$ y) accounted for $8.4 \%$ (5,065/ 60,209). Table 7 shows high risk pregnancy and perinatal morbidities in association with maternal school education years, where $1.5 \%$ were illiteracy.

\section{Perinatal complications and hospitalized neonatal patients} There were 6,872 neonates admitted to the ward including 4,332 male and 2,540 female (male-to-female ratio $1.71: 1$ ), in which $43 \%, 26.2 \%, 11.1 \%$ and $19.8 \%$ were admitted on day $1,2-7,8-14,15-28$, respectively, with $75 \%$ of the total as rural origin. In $18.8 \%$ of the hospitalized neonatal patients, their mother had pregnancy complications [14], and these incidences declined with increasing BW. For the pregnancy complications before delivery in the mothers of all hospitalized neonates, 547 (8.0\%) had premature rupture of the membrane, 248 (3.6\%) fever and infection, 160 (2.3\%) hypertension, 105 (1.5\%) preeclampsia, $77(1.1 \%)$ placenta previa, $40(0.6 \%)$ anemia or placenta abruption each, $29(0.4 \%)$ diabetes, $27(0.4 \%)$ liver diseases, $26(0.4 \%)$ hematological diseases, $17(0.2 \%)$ syphyllis, $14(0.2 \%)$ cardiac diseases, 7 systemic lupus erythematosus, 5 renal diseases, 4 epilepsy, 4 hyperthyroidism, 3 hypothyroidism, etc. In the hospitalized and critically ill neonatal patients, major diagnoses were severe sepsis and septic shock, diaphragmatic hernia, disseminated intravascular coagulation, pulmonary hemorrhage, cardiac failure, respiratory distress syndrome, pneumothorax, necrotizing enterocolitis, each with a mortality of $78.6 \%, 60 \%, 60 \%, 53.8 \%, 38.9 \%$, $18.9 \%, 17.0 \%$ and $9.1 \%$, respectively. In all these patients, $26.8 \%$ received oxygen therapy, $8.6 \%$ were mechanically ventilated, 99.2\% treated with antibiotics, 9.3\% corticosteroids, and $1.3 \%$ surfactant therapy, whereas $34.9 \%$ recovered, $56.2 \%$ improved, $4.8 \%$ requested own discharge, $2.4 \%$ were given up or died, $1.7 \%$ transferred to other hospitals. Average length of hospital stay was $8.5 \pm$ 6.3 days, and average cost of hospital stay was 4,182 \pm 4,033 Yuan (CNY, $6.5=1$ USD in 2010).

\section{Uni- and multi-variate logistic regression analysis of risks for perinatal mortality}

Table 8 illustrates the results from uni- (part A) and multi-variate (part B) binary logistic regression analysis of risks of perinatal mortality from clinical variables associated with pregnancy complications, perinatal morbidities and neonatal status. In both uni- and multi-variate logistic 
Table 3 Perinatal status and pregnancy complications in neonatal birthweight strata

\begin{tabular}{|c|c|c|c|c|c|}
\hline Birthweight (g) & $<1,500$ & $1,500-2,499$ & $2,500-3,999$ & $\geq 4,000$ & $P$ values \\
\hline Birth number (\%) & $154(0.3)$ & $1,537(2.5)$ & $50,450(83.6)$ & $8,231(13.6)$ & \\
\hline Males & $73(48.0)$ & $762(49.9)$ & $26,133(52.0)$ & $5,343(65.3)$ & $<0.001$ \\
\hline Gestational age (weeks) & $30.1 \pm 2.9$ & $35.9 \pm 2.9$ & $39.7 \pm 1.2$ & $40.2 \pm 1.0$ & $<0.001$ \\
\hline Birthweight (grams) & $1,157 \pm 238$ & $2,140 \pm 269$ & $3,365 \pm 333$ & $4,192 \pm 250$ & $<0.001$ \\
\hline Preterm births & $152(98.7)$ & $950(62.3)$ & $1,103(2.2)$ & $26(0.3)$ & $<0.001$ \\
\hline Multi-births & $28(18.2)$ & $323(21.0)$ & $729(1.4)$ & $23(0.3)$ & $<0.001$ \\
\hline Congenital anomalies & $11(7.1)$ & $54(3.5)$ & $222(0.4)$ & $27(0.3)$ & $<0.001$ \\
\hline Cesarean section rate & $43(28.3)$ & $748(49.0)$ & $25,629(50.9)$ & $5,438(66.2)$ & $<0.001$ \\
\hline Pregnancy complications & $65(42.2)$ & $476(31.0)$ & $4,769(9.4)$ & $710(8.6)$ & $<0.001$ \\
\hline Hypertension & $12(7.8)$ & $105(6.8)$ & $758(1.5)$ & $133(1.6)$ & $<0.001$ \\
\hline PROM & $25(16.2)$ & $236(15.4)$ & $2,678(5.3)$ & $336(4.1)$ & $<0.001$ \\
\hline Anemia & $3(1.9)$ & $40(2.6)$ & $590(1.2)$ & $110(1.3)$ & $<0.001$ \\
\hline Maternal age (years) & $26.6 \pm 6.3$ & $26.3 \pm 5.9$ & $25.7 \pm 5.1$ & $26.7 \pm 5.3$ & $<0.001$ \\
\hline Delayed childbearing & $22(14.5)$ & $192(12.6)$ & 3,971 (7.9) & $866(10.6)$ & $<0.001$ \\
\hline$>9$ years' education & $15(10.9)$ & $256(18.7)$ & $8,614(18.4)$ & $1,397(18.3)$ & 0.151 \\
\hline Amniotic fluid volume & & & & & $<0.001$ \\
\hline Normal & $123(83.7)$ & $1,273(86.9)$ & $45,686(92.5)$ & $7,608(94.5)$ & \\
\hline Polyhydramnios & $11(7.5)$ & $27(1.8)$ & $331(0.7)$ & $105(1.3)$ & \\
\hline Oligohydramnios & $13(8.8)$ & 165 (11.3) & 3,395 (6.9) & $342(4.2)$ & \\
\hline Amniotic contamination & & & & & $<0.001$ \\
\hline Normal & $121(80.1)$ & $1,259(84.3)$ & $43,144(86.2)$ & $6,841(83.9)$ & \\
\hline Grade I & $10(6.6)$ & $62(4.1)$ & $2,616(5.2)$ & $533(6.5)$ & \\
\hline Gradell & $4(2.6)$ & $68(4.5)$ & $2,273(4.5)$ & $391(4.8)$ & \\
\hline Grade III & $16(10.6)$ & $104(7.0)$ & $2,022(4.0)$ & $388(4.8)$ & \\
\hline \multicolumn{6}{|l|}{ Apgar score } \\
\hline $1-\min \leq 7$ & $107(74.3)$ & $449(29.7)$ & $1,509(3.0)$ & $212(2.6)$ & $<0.001$ \\
\hline $1-\min \leq 3$ & $59(41.0)$ & $115(7.6)$ & $153(0.3)$ & $17(0.2)$ & $<0.001$ \\
\hline $5-\min \leq 7$ & 91 (63.6) & 209 (13.9) & $209(0.4)$ & $27(0.3)$ & $<0.001$ \\
\hline $5-\min \leq 3$ & $45(31.5)$ & $88(5.8)$ & $89(0.2)$ & $12(0.1)$ & $<0.001$ \\
\hline Hospitalization & $121(78.6)$ & $1,209(78.7)$ & $4,880(9.7)$ & $637(7.7)$ & $<0.001$ \\
\hline Oxygen therapy & $103(66.9)$ & $565(36.8)$ & $1,043(2.1)$ & $122(1.5)$ & $<0.001$ \\
\hline Mechanical ventilation & $67(43.5)$ & $246(16.0)$ & $255(0.5)$ & $23(0.3)$ & $<0.001$ \\
\hline Postnatal steroids & $10(6.5)$ & $71(4.6)$ & $488(1.0)$ & $72(0.9)$ & $<0.001$ \\
\hline Surfactant therapy & $18(11.7)$ & $57(3.7)$ & 14 & 1 & $<0.001$ \\
\hline Pneumonia & $88(57.1)$ & $910(59.2)$ & $2,532(5.0)$ & $326(4.0)$ & $<0.001$ \\
\hline Asphyxia & $31(20.1)$ & $214(13.9)$ & $504(1.0)$ & $59(0.7)$ & $<0.001$ \\
\hline RDS & $56(36.4)$ & 178 (11.6) & $132(0.3)$ & 4 & $<0.001$ \\
\hline IVH & $50(32.5)$ & $468(30.4)$ & $670(1.3)$ & $62(0.8)$ & $<0.001$ \\
\hline Hyperbilirubinemia & $7(4.5)$ & $120(7.8)$ & $1448(2.9)$ & $202(2.5)$ & $<0.001$ \\
\hline Deaths $^{a}$ & $55(35.7)$ & $93(6.1)$ & $88(0.2)$ & $10(0.1)$ & $<0.001$ \\
\hline
\end{tabular}

All values are numbers and percentage (\% of total births in each birthweight category) or means $\pm S D$; ${ }^{a}$ including fetal deaths/stillbirth and neonatal deaths immediately at delivery but counted as live births.

Abbreviations: PROM premature rupture of membrane, RDS respiratory distress syndrome, IVH intraventricular hemorrhage. 
Table 4 Perinatal status and pregnancy complications in neonatal gestational age strata

\begin{tabular}{|c|c|c|c|c|c|}
\hline Gestational age (weeks) & $<32$ & $32-36$ & $37-41$ & $\geq 42$ & $P$ values \\
\hline All births ${ }^{a}$ & $302(0.5)$ & $1,937(3.2)$ & $56,331(93.5)$ & $1,694(2.8)$ & \\
\hline Males & $164(54.8)$ & $1,076(56.0)$ & $30,134(53.8)$ & $838(49.7)$ & 0.002 \\
\hline Gestational age (weeks) & $29.8 \pm 1.8$ & $35.3 \pm 1.3$ & $39.8 \pm 1.0$ & $42.4 \pm 0.5$ & $<0.001$ \\
\hline Birthweight (g) & $1,727 \pm 709$ & $2,572 \pm 562$ & $3,475 \pm 442$ & $3,596 \pm 443$ & $<0.001$ \\
\hline Low birthweight & $258(85.4)$ & $844(43.8)$ & $572(1.0)$ & $6(0.4)$ & $<0.001$ \\
\hline Multi-births & $37(12.3)$ & $334(17.2)$ & $705(1.3)$ & $9(0.5)$ & $<0.001$ \\
\hline Congenital anomalies & $25(8.4)$ & $38(2.0)$ & $243(0.4)$ & $7(0.4)$ & $<0.001$ \\
\hline Cesarean section & $73(24.6)$ & $960(49.8)$ & $29,697(52.8)$ & $1,082(64.0)$ & $<0.001$ \\
\hline Pregnancy complications & $101(34.0)$ & $759(39.3)$ & $5,086(9.1)$ & $90(5.3)$ & $<0.001$ \\
\hline Hypertension & $12(4.0)$ & $127(6.6)$ & $855(1.5)$ & $17(1.0)$ & $<0.001$ \\
\hline PROM & $54(17.9)$ & $427(22.0)$ & $2761(4.9)$ & $40(2.4)$ & $<0.001$ \\
\hline Anemia & $4(1.3)$ & $60(3.1)$ & $667(1.2)$ & $14(0.8)$ & $<0.001$ \\
\hline Maternal age (years) & $26.9 \pm 6.3$ & $26.7 \pm 5.9$ & $25.8 \pm 5.1$ & $25.1 \pm 5.0$ & $<0.001$ \\
\hline Delayed childbearing & $45(15.0)$ & $262(13.6)$ & $4,601(8.2)$ & $125(7.4)$ & $<0.001$ \\
\hline$>9$ years' education & $41(15.4)$ & $364(21.4)$ & $9,732(18.6)$ & $171(10.8)$ & $<0.001$ \\
\hline Amniotic fluid volume & & & & & $<0.001$ \\
\hline Normal & $242(84.6)$ & $1,651(90.1)$ & $51,189(92.8)$ & $1,484(89.3)$ & \\
\hline Polyhydramnios & $17(5.9)$ & $35(1.9)$ & $410(0.7)$ & $10(0.6)$ & \\
\hline Oligohydramnios & $27(9.4)$ & $147(8.0)$ & $3,561(6.5)$ & $168(10.1)$ & \\
\hline Amniotic contamination & & & & & $<0.001$ \\
\hline Normal & $239(81.3)$ & $1,679(89.3)$ & $48,041(86.0)$ & 1,295 (77.1) & \\
\hline Grade I & $15(5.1)$ & $70(3.7)$ & $2,986(5.3)$ & $140(8.3)$ & \\
\hline Grade II & $5(5.1)$ & $56(3.0)$ & $2,543(4.6)$ & $121(7.2)$ & \\
\hline Grade III & $25(8.5)$ & $75(4.0)$ & 2,305 (4.1) & $124(7.4)$ & \\
\hline 1 -min Apgar $\leq 7$ & $187(64.5)$ & $463(24.3)$ & $1,561(2.8)$ & $62(3.7)$ & $<0.001$ \\
\hline 1 -min Apgar $\leq 3$ & $98(33.8)$ & $99(5.2)$ & $143(0.3)$ & $5(0.3)$ & $<0.001$ \\
\hline 5-min Apgar $\leq 7$ & $152(52.4)$ & $179(9.4)$ & $198(0.4)$ & $8(0.5)$ & $<0.001$ \\
\hline 5-min Apgar $\leq 3$ & $80(27.6)$ & $75(3.9)$ & $72(0.1)$ & $4(0.2)$ & $<0.001$ \\
\hline Hospitalized rate & $208(68.9)$ & $1,445(74.6)$ & 4,961 (8.8) & $123(7.3)$ & $<0.001$ \\
\hline Oxygen therapy & $156(51.7)$ & $656(33.9)$ & $966(1.7)$ & $36(2.1)$ & $<0.001$ \\
\hline Mechanical ventilation & $111(36.8)$ & $253(13.1)$ & $206(0.4)$ & $9(0.5)$ & $<0.001$ \\
\hline Surfactant therapy & $33(10.9)$ & $49(2.5)$ & $8(0)$ & $0(0)$ & $<0.001$ \\
\hline Pneumonia & $167(55.3)$ & $1,064(54.9)$ & $2,494(4.4)$ & $69(4.1)$ & $<0.001$ \\
\hline Asphyxia & $59(19.5)$ & $232(12.0)$ & $493(0.9)$ & $16(0.9)$ & $<0.001$ \\
\hline RDS & $92(30.5)$ & $183(9.4)$ & $90(0.2)$ & $0(0)$ & $<0.001$ \\
\hline Deaths ${ }^{b}$ & $93(30.9)$ & $76(4.0)$ & $73(0.1)$ & $4(0.2)$ & $<0.001$ \\
\hline
\end{tabular}

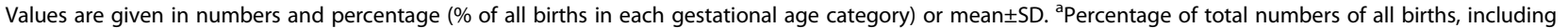

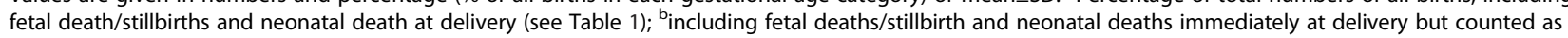
live births.

Abbreviations: PROM premature rupture of membrane; Apgar, Apgar score of life signs; RDS, respiratory distress syndrome.

regression analysis, $\mathrm{BD}$, low $\mathrm{GA}$ and $\mathrm{BW}$ are the three most significant contributing factors, indirectly reflecting the influence of pregnancy complications and other perinatal risks, whereas gender was not a contributing factor.

\section{Discussions}

This study estimated impact of overall high risk pregnancy and delivery at three levels of hospitals based on data file from complete birth population, stratified GA 
and BW of the neonates, and maternal mode of delivery, age and education, confirmed by uni- and multivariate logistic regression analyses of the risks of perinatal deaths. These results are evidences linking the major pregnancy complications to perinatal and neonatal morbidity and mortality, accounting in part for all the hospitalized neonates, and should be regarded as benchmark in this study field. These results should also be complementary to our previous report on perinatal and neonatal mortalities, premature birth rate, and consist of a detailed description of the perinatal care and delivery in a regional Chinese perinatal care system [14], and to the understanding of previous reports on the trend of neonatal mortality in China in comparison with the worldwide development [1-8]. The 151 level I-III hospitals in this region served for $>60,000$ annual deliveries from 5.4 millions of population, and their capacity and quality were very representative and close to average of the emerging regions in east and mid-land provinces of the country.

There was a clear trend of high risk pregnancy and delivery among three levels of hospitals in this region as reflected by differences of $\mathrm{BD}$, preterm births, multiple births, congenital anomalies, pregnancy complications, and stress of fetus and newborns at delivery. It is possible that there was limitation at low level hospitals in distinguishing these situations in daily practice, however, this was the first time reported as fetal death and stillbirth rate from Chinese regional complete data files of regional birth registry. There was a clear trend that higher pregnancy complications and fetal deaths (including stillbirth) and early neonatal death were found mainly in the level II and III hospital deliveries (Table 1). The mothers in the level III hospitals had 2-4 times as high the pregnancy complications contributing to fetal and neonatal adverse outcome and morbidity as those in the level I hospitals (Table 1). The $10 \%$ pregnancy complications in the whole births of this survey is similar to $11 \%$ in a previous, small scale survey of 5,822 live births in 2006-2007 in Julu county hospitals, of approximate 400,000 population, Hebei province, one of the coastal regions in China [18]. The specific pregnancy complications in this survey, such as pregnant associated hypertention and preeclampsia, anemia, placenta previa, diabetes and others, were lower than that in the international and domestic levels [19-24]. As $85 \%$ of the total deliveries were at level I and II hospitals with variable, but substantial, incidence of pregnancy complications, challenge exists as to inappropriate diagnosis and underreporting, and to what magnitude the overall perinatal risks may be reduced in association with multiple factors such as facilities, caregiver competence, service standard, health insurance, and socioeconomic and socio-cultural aspects, etc.
There is possibility that incidence of pregnancy complications in all the deliveries from the level I hospitals may be underreported even if the medical care for the complications was available there. Mechanisms underlying such situation were due to insufficient clinically diagnostic experience and management or inappropriate response for concerns of liability from more reporting of the pregnancy complications. Nevertheless, this would be common in regions where perinatal care system is not properly organized, and criteria for diagnosis and management of major pregnancy morbidities and complications were not uniformly executed $[7,8,10,13]$. These imply bias due to inappropriate diagnosis and incomplete data collection from some lower level hospitals, hence is direction of improvement in local infrastructure of perinatal and medical care for those with pregnancy complications, and information reporting system. Although in some well developed prefectural regions of the coastal provinces (such as in Zhejiang), delivery at level I hospital is no longer eligible in recent years, the delivery at level I hospital should remain for substantial proportion (20-40\%) of rural residents, especially in regions of low economic development and poor perinatal care conditions [11,12].

Mode of delivery was apparently associated with risks due to pregnancy complications [25-27] (Table 5). Those with C-section delivery had higher rate of pregnancy complications, especially premature rupture of the membrane and hypertension whereas multiple pregnancy and abnormal amniotic fluid volume were also associated. High C-section deliveries at level I and II hospitals should have contributed considerably to the overall $\mathrm{C}$-section rate, in which the non-medical indication related might be accounted for a substantial proportion, indicating it necessary to standardize routine service at lower level obstetrics. Our current data reveal that a high C-section rate above $50 \%$ was seen in those with maternal age 20-34 years, no pregnancy complications, no BD or congenital anomalies, no amniotic fluid contaminations or abnormal volume, suggesting substantial numbers of delivery by $\mathrm{C}$-section had no medical indications, or as low risk pregnancy. The morbidity in the neonates hospitalized tended to be severe and complicated in C-section deliveries as more required oxygen therapy and mechanical ventilation, and more respiratory distress syndrome and CHD were found. Although those delivered at level I and II hospitals accounted for almost $2 / 3$ of pregnancy complications in the total (Table 1), as we did not have the data on severity of pregnancy complications in these hospitals, more severe pregnancy complications should have been centered and managed in the level III hospitals. This trend should have been more prominent and relevant in the emerging regions, requiring advanced perinatal care system emphasizing on routine screening services for risk 
Table $\mathbf{5}$ Mode of delivery related perinatal status, complications and neonatal morbidities

\begin{tabular}{|c|c|c|c|}
\hline Mode of delivery & Vaginal $^{b}$ & Cesarean section & $P$ values \\
\hline All births ${ }^{a}$ & $28,481(47.1)$ & $31,964(52.9)$ & \\
\hline Males & $14,683(51.8)$ & $17,640(55.4)$ & $<0.001$ \\
\hline Gestational age (weeks) & $39.6 \pm 1.6$ & $39.7 \pm 1.4$ & $<0.001$ \\
\hline Birthweight (grams) & $3,387 \pm 475$ & $3,488 \pm 500$ & $<0.001$ \\
\hline Preterm births & $1,191(4.2)$ & $1,033(3.2)$ & $<0.001$ \\
\hline Low birthweight & $887(3.1)$ & $791(2.5)$ & $<0.001$ \\
\hline Multi-births & $242(0.9)$ & $844(2.6)$ & $<0.001$ \\
\hline Congenital anomalies & $142(0.5)$ & $171(0.5)$ & 0.519 \\
\hline Pregnancy complications & $1,715(6.0)$ & $4,315(13.5)$ & $<0.001$ \\
\hline Hypertension & $215(0.8)$ & $797(2.5)$ & $<0.001$ \\
\hline PROM & $1,045(3.7)$ & $2,234(7.0)$ & $<0.001$ \\
\hline Anemia & $273(1.0)$ & $470(1.5)$ & $<0.001$ \\
\hline Maternal age (years) & $25.5 \pm 5.0$ & $26.2 \pm 5.2$ & $<0.001$ \\
\hline Delayed childbearing & $2,110(7.5)$ & $2,948(9.3)$ & $<0.001$ \\
\hline$>9$ years' education & $4,451(16.8)$ & $5,851(19.8)$ & $<0.001$ \\
\hline Amniotic fluid volume & & & $<0.001$ \\
\hline Normal & $26,999(96.5)$ & $27,774(89.1)$ & \\
\hline Polyhydramnios & $150(0.5)$ & $325(1.0)$ & \\
\hline Oligohydramnios & $837(3.0)$ & $3,072(9.9)$ & \\
\hline Amniotic contamination & & & $<0.001$ \\
\hline Normal & $24,569(86.6)$ & $26,877(85.1)$ & \\
\hline Grade I & $1,476(5.2)$ & $1,753(5.6)$ & \\
\hline Grade II & $1,146(4.0)$ & $1,594(5.0)$ & \\
\hline Grade III & $1,178(4.2)$ & $1,354(4.3)$ & \\
\hline \multicolumn{4}{|l|}{ Apgar score } \\
\hline $1-\min \leq 7$ & $1,253(4.4)$ & $1,024(3.2)$ & $<0.001$ \\
\hline $1-\min \leq 3$ & $256(0.9)$ & $88(0.3)$ & $<0.001$ \\
\hline $5-\min \leq 7$ & $367(1.3)$ & $170(0.5)$ & $<0.001$ \\
\hline $5-\min \leq 3$ & $189(0.7)$ & $42(0.1)$ & $<0.001$ \\
\hline Hospitalization & $3,137(11.0)$ & $3,715(11.6)$ & 0.019 \\
\hline Oxygen therapy & $777(2.7)$ & $1,056(3.3)$ & $<0.001$ \\
\hline Mechanical ventilation & $205(0.7)$ & $387(1.2)$ & $<0.001$ \\
\hline Postnatal corticosteroids & $284(1.0)$ & $358(1.1)$ & 0.076 \\
\hline Surfactant use & $34(0.1)$ & $56(0.2)$ & 0.047 \\
\hline Pneumonia & $1,779(6.2)$ & $2,080(6.5)$ & 0.098 \\
\hline Jaundice ${ }^{c}$ & $892(3.1)$ & $887(2.8)$ & 0.010 \\
\hline Asphyxia & $357(1.3)$ & $451(1.4)$ & 0.092 \\
\hline Intraventricular hemorrhage & $593(2.1)$ & $655(2.1)$ & 0.776 \\
\hline Hypoxic-ischemic encephalopathy & $557(2.0)$ & $711(2.2)$ & 0.021 \\
\hline Sepsis & $736(2.6)$ & $815(2.5)$ & 0.789 \\
\hline Congenital heart disease & $183(0.6)$ & $340(1.1)$ & $<0.001$ \\
\hline Respiratory distress syndrome & $123(0.4)$ & $248(0.8)$ & $<0.001$ \\
\hline
\end{tabular}


Table 5 Mode of delivery related perinatal status, complications and neonatal morbidities (Continued)

\begin{tabular}{llll}
\hline Cephalohematoma & $216(0.8)$ & $39(0.1)$ & $<0.001$ \\
ABO hemolysis & $105(0.4)$ & $108(0.3)$ & 0.285 \\
Deaths $^{d}$ & $202(0.7)$ & $42(0.1)$ & $<0.001$ \\
\hline
\end{tabular}

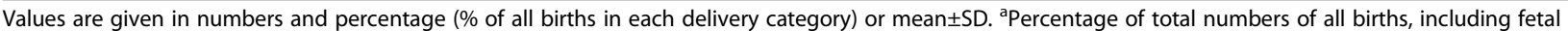
death/stillbirths and neonatal death at delivery (see Table 1); ${ }^{\text {including }} 397$ with assisted operation procedures; ${ }^{c_{i n c l u d i n g}}$ hyperbilirubinemia; ${ }^{{ } \text {including fetal }}$ deaths/stillbirth and neonatal deaths immediately at delivery but counted as live births.

Abbreviations: PROM premature rupture of membrane, Apgar Apgar score of life signs.

factors associated with adverse pregnancy along with a close follow-up for pregnancy women at risk of observed pregnancy complications during prenatal care to minimize risk of pregnancy complications, hence possibility of C-section delivery reduction.
The social, cultural and economic factors may have influenced the regional perinatal and neonatal outcome. This study focused on mode of delivery, maternal age and education status. Maternal age should be an overt factor contributing to perinatal risks and neonatal outcome

Table 6 Maternal age related perinatal status and complications

\begin{tabular}{|c|c|c|c|c|}
\hline Maternal age, years & $<20$ & $20-34$ & $\geq 35$ & $P$ values \\
\hline Live births, $\mathrm{n}(\%)^{\mathrm{a}}$ & $1,490(2.5)$ & $53,654(89.1)$ & $5,065(8.4)$ & \\
\hline Males & $761(51.2)$ & $28,667(53.7)$ & $2,763(54.8)$ & 0.054 \\
\hline Gestational age (weeks) & $39.7 \pm 1.7$ & $39.7 \pm 1.5$ & $39.4 \pm 1.7$ & $<0.001$ \\
\hline Birthweight (grams) & $3,329 \pm 478$ & $3,442 \pm 485$ & $3,465 \pm 552$ & $<0.001$ \\
\hline Preterm birth rate & $74(5.0)$ & $1,847(3.5)$ & $307(6.1)$ & $<0.001$ \\
\hline Low birthweight & $56(3.8)$ & $1,406(2.6)$ & $214(4.2)$ & $<0.001$ \\
\hline Multi-births & $18(1.2)$ & $939(1.8)$ & $121(2.4)$ & 0.001 \\
\hline Congenital anomalies & $5(0.3)$ & $273(0.5)$ & $33(0.7)$ & 0.245 \\
\hline Cesarean section rate & $672(45.1)$ & $28,141(52.6)$ & $2,948(58.3)$ & $<0.001$ \\
\hline Pregnancy complications & $138(9.3)$ & $5,162(9.6)$ & $717(14.2)$ & $<0.001$ \\
\hline Hypertension & $15(1.0)$ & $795(1.5)$ & $200(3.9)$ & $<0.001$ \\
\hline PROM & $75(5.0)$ & $2,920(5.4)$ & $280(5.5)$ & 0.757 \\
\hline Anemia & $17(1.1)$ & $637(1.2)$ & $89(1.8)$ & 0.002 \\
\hline Maternal age (years) & $18.6 \pm 0.6$ & $24.9 \pm 3.6$ & $38.0 \pm 2.5$ & $<0.001$ \\
\hline$>9$ years' education & $62(4.4)$ & $9,827(19.7)$ & $401(8.5)$ & $<0.001$ \\
\hline Amniotic fluid volume & & & & 0.005 \\
\hline Normal & $1,344(92.0)$ & $48,608(92.6)$ & $4,568(92.3)$ & \\
\hline Polyhydramnios & $16(1.1)$ & $396(0.7)$ & $61(1.2)$ & \\
\hline Oligohydramnios & $101(6.9)$ & $3,490(6.6)$ & $318(6.4)$ & \\
\hline Amniotic contamination & & & & $<0.001$ \\
\hline Normal & $1,245(84.1)$ & $45,731(86.0)$ & $4,245(84.6)$ & \\
\hline Grade I & $93(6.3)$ & $2,843(5.3)$ & $267(5.3)$ & \\
\hline Grade ॥ & $84(5.7)$ & $2,412(4.5)$ & $234(4.7)$ & \\
\hline Grade III & $58(3.9)$ & $2,196(4.1)$ & $269(5.4)$ & \\
\hline \multicolumn{5}{|l|}{ Apgar score } \\
\hline $1-\min \leq 7$ & $69(4.6)$ & $1,961(3.7)$ & $249(4.9)$ & $<0.001$ \\
\hline $1-\min \leq 3$ & $14(0.9)$ & $280(0.5)$ & $52(1.0)$ & $<0.001$ \\
\hline $5-\min \leq 7$ & $22(1.5)$ & $443(0.8)$ & $73(1.5)$ & $<0.001$ \\
\hline $5-\min \leq 3$ & $13(0.9)$ & $181(0.3)$ & $40(0.8)$ & $<0.001$ \\
\hline Deaths $^{b}$ & $10(0.7)$ & $203(0.4)$ & $34(0.7)$ & 0.002 \\
\hline
\end{tabular}

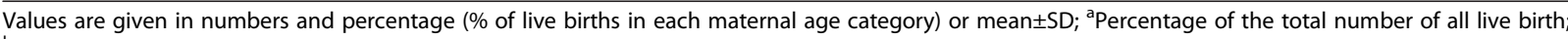

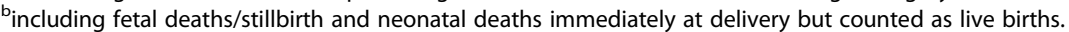

Abbreviations: PROM premature rupture of membrane. 
Table 7 Maternal education related perinatal status and complications

\begin{tabular}{|c|c|c|c|c|c|}
\hline Education years & $>12$ & $10-12$ & $7-9$ & $<7$ & $P$ values \\
\hline All births ${ }^{a}$ & $4,396(7.8)$ & $5,943(10.6)$ & $39,702(70.5)$ & $6,249(11.1)$ & \\
\hline Males & $2,319(53.4)$ & $3,056(51.9)$ & $21,318(53.9)$ & $3,388(54.4)$ & 0.017 \\
\hline Gestational age (weeks) & $39.5 \pm 1.4$ & $39.6 \pm 1.5$ & $39.7 \pm 1.5$ & $39.6 \pm 1.7$ & $<0.001$ \\
\hline Birthweight (g) & $3,462 \pm 472$ & $3,447 \pm 485$ & $3,446 \pm 485$ & $3,402 \pm 524$ & $<0.001$ \\
\hline Preterm birth rate & $157(3.6)$ & $248(4.2)$ & $1,254(3.2)$ & $307(5.0)$ & $<0.001$ \\
\hline Low birthweight & $108(2.5)$ & $163(2.8)$ & $996(2.5)$ & $240(3.8)$ & $<0.001$ \\
\hline Multi-births & $86(2.0)$ & $93(1.6)$ & $673(1.7)$ & $130(2.1)$ & 0.073 \\
\hline Congenital anomalies & $21(0.5)$ & $34(0.6)$ & $190(0.5)$ & $47(0.8)$ & 0.041 \\
\hline Cesarean section & $2,609(59.6)$ & $3,242(54.7)$ & $20,657(52.1)$ & 3,093 (49.6) & $<0.001$ \\
\hline Pregnancy complications & $634(14.6)$ & $715(12.1)$ & $3,310(8.4)$ & $616(9.9)$ & $<0.001$ \\
\hline Pregnant hypertension & $72(1.6)$ & $104(1.7)$ & $594(1.5)$ & $157(2.5)$ & $<0.001$ \\
\hline PROM & $432(9.8)$ & $427(7.2)$ & $1,827(4.6)$ & $258(4.1)$ & $<0.001$ \\
\hline Pregnant anemia & $44(1.0)$ & $92(1.5)$ & $420(1.1)$ & $93(1.5)$ & $<0.001$ \\
\hline Maternal age (years) & $26.8 \pm 3.0$ & $25.5 \pm 4.3$ & $25.3 \pm 4.9$ & $28.9 \pm 7.0$ & $<0.001$ \\
\hline Delayed childbearing & $106(2.4)$ & $295(5.0)$ & $2,713(6.9)$ & $1,590(25.5)$ & $<0.001$ \\
\hline Amniotic fluid volume & & & & & 0.259 \\
\hline Normal & $3,856(92.1)$ & $5,395(93.5)$ & $36,223(92.9)$ & $5,665(92.6)$ & \\
\hline Polyhydramnios & $31(0.7)$ & $34(0.6)$ & $283(0.7)$ & $47(0.8)$ & \\
\hline Oligohydramnios & $298(7.1)$ & $344(6.0)$ & $2,492(6.4)$ & 406 (6.6) & \\
\hline Amniotic contamination & & & & & $<0.001$ \\
\hline Normal & $3,750(87.5)$ & $5,083(86.7)$ & $33,942(86.1)$ & $5,283(85.1)$ & \\
\hline Grade I & $170(4.0)$ & $253(4.3)$ & $2,154(5.5)$ & $372(6.0)$ & \\
\hline Grade II & $150(3.5)$ & $247(4.2)$ & $1,816(4.6)$ & $303(4.9)$ & \\
\hline Grade III & $218(5.1)$ & $283(4.8)$ & 1,518 (3.8) & $250(4.0)$ & \\
\hline 1-min Apgar $\leq 7$ & $219(5.0)$ & $195(3.3)$ & $1,413(3.6)$ & $269(4.3)$ & $<0.001$ \\
\hline 1 -min Apgar $\leq 3$ & $16(0.4)$ & $26(0.4)$ & $207(0.5)$ & $68(1.1)$ & $<0.001$ \\
\hline 5-min Apgar $\leq 7$ & $44(1.0)$ & $37(0.6)$ & $308(0.8)$ & $92(1.5)$ & $<0.001$ \\
\hline 5-min Apgar $\leq 3$ & $8(0.2)$ & $16(0.3)$ & $145(0.4)$ & $49(0.8)$ & $<0.001$ \\
\hline Deaths $^{b}$ & $8(0.2)$ & $17(0.3)$ & $155(0.4)$ & $55(0.9)$ & $<0.001$ \\
\hline
\end{tabular}

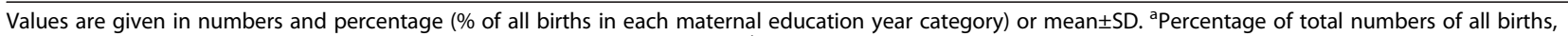

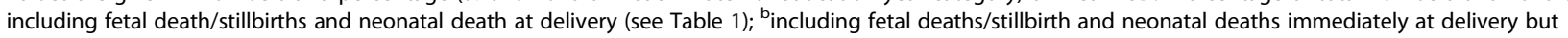
counted as live births.

Abbreviations: PROM premature rupture of membrane, Apgar Apgar score of life signs.

[28-32]. In those with early $(<20$ years old) and delayed $(\geq 35$ y) child bearing, relatively higher preterm birth rate (5\% and 6.1\%, respectively) were found (Table 6), along with higher rate of $\mathrm{BD}$, pregnancy complications, C-section rate, lower Apgar score at 1- and $5 \mathrm{~min}$, neonatal deaths rate, mainly seen in those $\geq 35 \mathrm{y}$. Maternal education years also had impact on pregnancy complications and neonatal outcome [33]. We found those with education $<7$ years had relatively higher percentage of delayed child bearing age (i.e., having more than 2 children), preterm births, low BW, lower Apgar score at 1- and $5 \mathrm{~min}$, neonatal deaths rate (Table 7). It is reported that the incidence of fetal and infant mortality were inversely related to maternal educational gradient: higher with a lower level of education, a determinant of the incidence of fetal and post-neonatal death but not of early and late neonatal death (0-27 days) [33]. Taking the results from uni- and multi-variate logistic regression analysis, pregnancy complications as well as multiple births, BD, and perinatal morbidities and mothers' biological and social status were significantly associated with the perinatal and neonatal outcome, indirectly reflecting the influence of pregnancy complications and other perinatal risks.

For limitation and implication of the study, as discussed above, in addition to incomplete data from lower level clinics, there are several major limitations of the data presentation. First, there is a lacking of causal relationship between those of maternal complications and 
Table 8 Uni- and multi-variate regression analysis of risk factors for perinatal mortality

\begin{tabular}{|c|c|c|c|c|c|}
\hline \multicolumn{6}{|c|}{ A. Uni-variate regression analysis for perinatal mortality } \\
\hline Variables & Category & Mortality (\%)* & OR & $95 \% \mathrm{Cl}$ & $P$ values \\
\hline \multirow[t]{2}{*}{ Gender } & Male & 0.4 & 1.154 & $0.898-1.481$ & 0.262 \\
\hline & Female & 0.4 & & & \\
\hline \multirow[t]{2}{*}{ Multi-births } & No & 0.4 & 3.984 & $2.426-6.543$ & $<0.001$ \\
\hline & Yes & 1.5 & & & \\
\hline \multirow[t]{2}{*}{ Congenital anomalies } & No & 0.3 & 74.260 & 54.067-101.996 & $<0.001$ \\
\hline & Yes & 19.2 & & & \\
\hline \multirow[t]{2}{*}{ Pregnancy complications } & No & 0.4 & 2.496 & $1.844-3.377$ & $<0.001$ \\
\hline & Yes & 0.9 & & & \\
\hline \multirow[t]{2}{*}{ Birthweight (grams) } & $\geq 2500$ & 0.2 & 57.700 & $44.478-74.852$ & $<0.001$ \\
\hline & $<2500$ & 8.8 & & & \\
\hline \multirow[t]{2}{*}{ Gestational age (weeks) } & $\geq 37$ & 0.1 & 61.782 & $47.019-81.180$ & $<0.001$ \\
\hline & $<37$ & 7.6 & & & \\
\hline \multirow[t]{2}{*}{ Maternal education (years) } & $\geq 10$ & 0.2 & 1.888 & $1.247-2.860$ & 0.002 \\
\hline & $<10$ & 0.5 & & & \\
\hline \multirow[t]{2}{*}{ Maternal age (years) } & $<35$ & 0.4 & 1.743 & $1.212-2.506$ & 0.002 \\
\hline & $\geq 35$ & 0.7 & & & \\
\hline \multirow[t]{2}{*}{ Amniotic contamination } & No & 0.2 & 8.374 & $6.454-10.864$ & $<0.001$ \\
\hline & Yes & 1.6 & & & \\
\hline \multirow[t]{2}{*}{ Amniotic fluid volume } & Normal & 0.3 & 4.894 & $3.661-6.542$ & $<0.001$ \\
\hline & Abnormal & 1.5 & & & \\
\hline
\end{tabular}

\section{B. Multi-variate regression analysis for perinatal mortality}

\begin{tabular}{|c|c|c|c|c|c|}
\hline \multirow[b]{2}{*}{ Variables } & \multirow[b]{2}{*}{ Reference $^{* *}$} & \multirow[b]{2}{*}{ OR } & \multicolumn{3}{|c|}{$95 \% \mathrm{Cl}$} \\
\hline & & & Lower & Upper & $P$ values \\
\hline Gender & Male & 1.240 & 0.896 & 1.715 & 0.194 \\
\hline Multi-births & No & 2.396 & 1.196 & 4.799 & 0.014 \\
\hline Congenital anomalies & No & 35.200 & 20.304 & 61.026 & $<0.001$ \\
\hline Pregnancy complications & No & 1.900 & 1.215 & 2.969 & 0.005 \\
\hline Birthweight (grams) & $\geq 2500$ & 5.397 & 3.458 & 8.442 & $<0.001$ \\
\hline Gestational age (weeks) & $\geq 37$ & 32.305 & 20.463 & 50.998 & $<0.001$ \\
\hline Education years & $\geq 10$ & 1.789 & 1.058 & 3.027 & 0.030 \\
\hline Maternal age (years) & $<35$ & 1.133 & 0.694 & 1.847 & 0.618 \\
\hline Amniotic contamination & No & 10.995 & 7.824 & 15.452 & $<0.001$ \\
\hline Amniotic fluid volume & Normal & 2.354 & 1.583 & 3.502 & $<0.001$ \\
\hline
\end{tabular}

*Mortality denotes those numbers of fetal deaths, stillbirths and early neonatal deaths in each category based on the total numbers of deaths listed in Table 1,2 , $3,4,5,6$ and 7 .

${ }^{*}$ As references of the opposite category of corresponding variables in this table part $A$.

Abbreviations: $\mathrm{OR}$ odds ratio, $\mathrm{Cl}$ confidence interval of $\mathrm{OR}$.

corresponding neonatal outcome. Secondly, there is a lacking of clues for severity of the pregnancy complications and their child delivery hospital levels. To analyze and understand these relationships, it may help to define the function and capacity of perinatal care at level II and III hospital, and standardize the care with license for maternal and neonatal care, corresponding delivery and medical facilities, potentiating enormous social health cost-effectiveness assessment and follow-up analysis in clinical economics. Thirdly, the study results do not reflect efficacy of specific measurements in the regional perinatal care system with local conditions that might have restricted more efficient infrastructure building up. For example, delivery was disseminated in 129 level I hospitals, and low Apgar score and neonatal deaths were still present to certain extent in all the births. Acquisition of 
adequate perinatal information tended to be difficult when we scrutinized $20 \%$ of the reported case records of all the births during the two major inspections of the survey, suggesting that the centralized deliveries at level II and III hospitals, and some upgraded level I hospitals, should be the direction of future development of the regional perinatal care system. Although the data may not be used to predict single hospital service quality, it may be used to compare different regions in health care standard and development. We consider current survey should be replicable from different regional data file to provide more reliable and comprehensive estimation of perinatal and neonatal morbidity and mortality and related high risk pregnancy, including cohort study of high risk pregnancy, delivery and neonatal outcome.

\section{Conclusion}

In conclusion, this survey demonstrates pregnancy complications and related perinatal morbidity as risk factors impacting on neonatal outcome, associated with hospital levels, maternal status, mode of delivery and major neonatal pathologies. We anticipate that more surveys are needed using the same concept and methodology in different regions to generate more comprehensive database and explore causal relations of high risk pregnancy to neonatal care and outcome, thereby ensuring development of measures and programs for the improvement by perinatal and neonatal care givers, policy makers and administrators for woman and infant health.

\section{Abbreviations \\ BD: Birth defects; BW: Birth weight; CHD: Congenital heart disease; \\ GA: Gestational age.}

\section{Competing interests}

The authors declare that they have no competing interests.

\section{Authors' contributions}

BS and HY were involved in conception, design and operation of the study, and edited and finalized the manuscript. LS coordinated the study, analyzed the data and drafted the first manuscript. $L H, Z T, M Q, S L, C S$, JL, YF, SL, MD, $X Z, Y Z, W L$ and $J X$ served as local co-investigator, contributed to data acquisition, analysis and interpretation. All authors read and approved the final manuscript.

\section{Acknowledgement}

The following investigators and institutions participated in the study as Huai'an Perinatal-Neonatal Study Group: Children's Hospital of Fudan University, Shanghai (Bo Sun [study director and principal investigator], Libo Sun [coordinator], Liling Qian); Huai'an Women and Children's Hospital, Huai'an (Hongni Yue [study co-director], Liangrong Han, Meihua Qi, Wenjie Zhang, Yue Zhou, Xiaogin Zhu, Bin Li); Huai'an First General Hospital, Huai'an (Zhaofang Tian, Shuyan Lu, Ping Bo, Zhimin Zhang); Huai'an Second General Hospital, Huai'an (Chunming Shan, Jianxin Luo, Juan Yang); Huaiyin District Hospital, Huai'an (Yujin Fan, Shouzhong Li, Guirong Wang); Chuzhou District Hospital, Huai'an (Maotian Dong, Yuhua Ding, Yaomei Zhu); Lianshui County Hospital, Huai'an (Xiaofeng Zuo, Xiaoyun Xu, Tingting Yin, Junzhang, Zhuang); Lianshui County Hospital for Traditional Chinese Medicine, Huai'an (Jinchun Shi); Xuyi County Hospital, Huai'an (Yixing Zhang, Sumei Zhang); Xuyi County Hospital for Traditional Chinese Medicine, Huai'an (Wenlong Lin, Bu Xu); Hongze County Hospital, Huai'an,
(Jinzhong Xu, Cuiping Yuan, Bin Cai); Jinhu County Hospital, Huai'an (Yongbo Heng, Ermei Lin); Jinhu County Hospital for Traditional Chinese Medicine, Huai'an (Zhihui Zhao); Lianshui County Hospital for Traditional Chinese Medicine, Huai'an (Wenkai Zou); Chuzhou Women and Children's Hospital, Huai'an (Li Zhang, Yanping Li, Chunhua Zhang); Hongze Women and Children's Hospital, Huai'an (Fenglin Qin); Huaiyin Women and Children's Hospital, Huai'an (Shaoping Yang); Jinhu Women and Children's Hospital, Huai'an (Shixiang Shi); Lianshui Women and Children's Hospital, Huai'an (Yaozhong Shen, Lijuan Sun, Bi Xue); Xuyi Women and Children's Hospital, Huai'an (Zhiping Pan, Hua Cao); Huai'an Third General Hospital, Huai'an (Airong Sheng); Huai'an Hospital for Traditional Chinese Medicine, Huai'an (Yongjian Wu); First Branch of Huai'an First General Hospital, Huai'an (Yani Lei); No. 82 Hospital of Chinese People's liberation Army, Huai'an (Tao Xu); and other staffs from level I clinics.

The authors are grateful to Dr. Xunli Yin, Fei Zhao,Yongliang Feng, Die Shu and Junyi Jiang, from the Institute of Family Planning, School of Public Health, Fudan University, for advice and discussion and assistance in data input and analysis.

This study was supported in part by grants from the NSFC-CIHR joint health research program (No. 30611120518); the Project 211 (phase III) and the Doctorate Research Project (No. 20090071110061), Ministry of Education; the Project for Institutional Development in Laboratory of Neonatal Medicine, Ministry of Health; Shanghai Municipal Department of Health (No. L06038); and China Medical Board of New York (No. 03-786).

\section{Author details}

'Departments of Pediatrics and Neonatology, Children's Hospital and the Institutes of Biomedical Science, Fudan University, and the Laboratory of Neonatal Medicine, National Health and Family Planning Commission, Shanghai 201102, China. ${ }^{2}$ Departments of Neonatology and Obstetrics, Huai'an Women and Children's Hospital, Huai'an, Jiangsu 223002, China. ${ }^{3}$ Departments of Neonatology and Obstetrics, Huai'an First People's Hospital, Huai'an, Jiangsu 223002, China. ${ }^{4}$ Departments of Pediatrics and Obstetrics, Huai'an Second People's Hospital, Huai'an, Jiangsu 223002, China.

${ }^{5}$ Departments of Pediatrics and Obstetrics, Huaiyin District Hospital, Huai'an, Jiangsu 223300, China. ${ }^{6}$ Departments of Pediatrics and Obstetrics, Chuzhou District Hospital, Huai'an, Jiangsu 223200, China. ${ }^{7}$ Departments of Pediatrics and Obstetrics, Lianshui County Hospital, Huai'an, Jiangsu 223400, China. ${ }^{8}$ Departments of Pediatrics and Obstetrics, Xuyi County Hospital, Huai'an, Jiangsu 211700, China. ${ }^{9}$ Departments of Pediatrics and Obstetrics, Xuyi County Hospital for Traditional Chinese Medicine, Huai'an, Jiangsu 211700 , China. ${ }^{10}$ Departments of Pediatrics and Obstetrics, Hongze County Hospital, Huai'an, Jiangsu 223100, China. "'Departments of Pediatrics and Obstetrics, Jinhu County Hospital, Huai'an, Jiangsu 211600, China.

Received: 17 March 2014 Accepted: 22 September 2014 Published: 30 September 2014

\section{References}

1. Rajaratnam JK, Marcus JR, Flaxman AD, Wang H, Levin-Rector A, Dwyer L, Costa M, Lopez AD, Murray CJ: Neonatal, postneonatal, childhood, and under-5 mortality for 187 countries, 1970-2010: a systematic analysis of progress towards Millennium Development Goal 4. Lancet 2010, 375:1988-2008.

2. Wang YP, Miao L, Dai L, Zhou GX, He CH, Li XH, Li Q, Li MR, Zhu J, Liang J: Mortality rate for children under 5 years of age in China from 1996 to 2006. Public Health 2011, 125:301-307.

3. Feng J, Yuan XQ, Zhu J, Li XH, Miao L, He CH, Wang YP: Under-5-mortality rate and causes of death in China, 2000 to 2010. Zhonghua Liu Xing Bing Xue Za Zhi 2012, 33:558-561.

4. Rudan I, Chan KY, Zhang JS, Theodoratou E, Feng XL, Salomon JA, Lawn JE, Cousens S, Black RE, Guo Y, Campbell H, WHO/UNICEF's Child Health Epidemiology Reference Group (CHERG): Causes of deaths in children younger than 5 years in China in 2008. Lancet 2010, 375:1083-1089.

5. Feng XL, Guo S, Hipgrave D, Zhu J, Zhang L, Song L, Yang Q, Guo Y, Ronsmans C: China's facility-based birth strategy and neonatal mortality: a population-based epidemiological study. Lancet 2011, 378:1493-1500.

6. Feng XL, Theodoratou E, Liu L, Chan KY, Hipgrave D, Scherpbier R, Brixi H, Guo S, Chunmei W, Chopra M, Black RE, Campbell H, Rudan I, Guo Y: Social, economic, political and health system and program determinants of child mortality reduction in China between 1990 and 2006: a systematic analysis. J Glob Health 2012, 2:10405. 
7. Liang J, Zhen X, Zhu J, Mu D, Li X, Li Y, He C, Miao L, Lu Z, Wang Y: Neonatal infection-associated mortality in China, a population-based study, 2003-2008. J Matern Fetal Neonatal Med 2012, 25:2750-2755.

8. Wang Y, Zhu J, He C, Li X, Miao L, Liang J: Geographical disparities of infant mortality in rural China. Arch Dis Child Fetal Neonatal Ed 2012, 97:285-290.

9. Xu T, Wang HS, Ye HM, Yu RJ, Huang XH, Wang DH, Wang LX, Feng Q, Gong LM, Ma Y, Keenan W, Niermeyer S: Impact of a nationwide training program for neonatal resuscitation in China. Chin Med J (Engl) 2012, 125:1448-1456.

10. Zhu $X Y$, Huang ZJ, Liu LR, Cui ZL: Factor analysis on trend of infant mortality and maternal health management in Henan province from 2000 to 2010. Zhonghua Liu Xing Bing Xue Za Zhi 2012, 33:930-932.

11. Zhang $W F, X u Y H$, Yang $R L$, Zhao ZY: Indicators of child health, service utilization and mortality in Zhejiang Province of China, 1998-2011. PLOS One 2013, 8:e62854.

12. Wax JR: In China, hospital births are associated with a $62 \%$ decreased risk of neonatal mortality. Evid Based Med 2012, 17:9.

13. Huo K, Zhao Y, Feng H, Yao M, Sävman K, Wang X, Zhu C: Mortality rates of children aged under five in Henan province, China, 2004-2008. Paediatr Perinat Epidemiol 2010, 24:343-348.

14. Sun L, Yue H, Sun B, Han L, Qi M, Tian Z, Sun L, Yue H, Sun B, Han L, Qi M, Tian Z, Lu S, Shan C, Luo J, Fan Y, Li S, Dong M, Zuo X, Zhang Y, Lin W, Xu J, Heng Y, Huai'an Perinatal-Neonatal Study Group: Estimation of birth population-based perinatal-neonatal mortality and preterm rate in China from a regional survey in 2010. J Matern Fetal Neonatal Med 2013, 26:1641-1648

15. World Health Organization: International statistical classification of disease and related health problems. 10th revision (ICD-10). Geneva: 1993.

16. Cunninghan FG, Gant NF, Leveno KJ, Gilstrap LC, Hauth JC, Wenstrom KD (Eds): Williams Obstetrics. 21st edition. New York: McGraw-Hill; 2001.

17. Fanaroff AA, Richard M: Neonatal-Perinatal Medicine. Disease of the fetus and infant. 7th edition. St. Louis: Mosby; 2002.

18. Ma L, Liu CQ, Zheng XL, Xin SF, Ji ZL, Li YM, Yan GP, Tian CF, Tang LM, Sun $B$ : A 12-month prospective survey of perinatal outcome of livebirth neonates in Julu County, China. Chin Med J (Engl) 2010, 123:2781-2785.

19. Gong J, Savitz DA, Stein CR, Engel SM: Maternal ethnicity and pre-eclampsia in New York City, 1995-2003. Paediatr Perinat Epidemiol 2012, 26:45-52.

20. Khambalia AZ, Ford JB, Nassar N, Shand AW, McElduff A, Roberts CL: Occurrence and recurrence of diabetes in pregnancy. Diabetes Med 2013, 30:452-456

21. Walker RL, Hemmelgarn B, Quan H: Incidence of gestational hypertension in the Calgary Health Region from 1995 to 2004. Can J Cardiol 2009, 25:284-287.

22. Wallis $A B$, Saftlas AF, Hsia J, Atrash HK: Secular trends in the rates of preeclampsia, eclampsia, and gestational hypertension, United States, 1987-2004. Am J Hypertens 2008, 21:521-526.

23. Zhao GQ, Li B, Tian FL, Xia JH, Ou YH: An epidemiological survey on obstetric emergency and relative complications in Guangdong Province. Zhonghua Liu Xing Bing Xue Za Zhi 2006, 27:570-574.

24. Ezugwu EC, Mbah BO, Chigbu CO, Onah HE: Anaemia in pregnancy: a public health problem in Enugu, South-east Nigeria. J Obstet Gynaecol 2013, 33:451-454.

25. Zhang J, Liu Y, Meikle S, Zheng J, Sun W, Li Z: Cesarean delivery on maternal request in Southeast China. Obstet Gynecol 2008, 111:1077-1082.

26. Lumbiganon P, Laopaiboon M, Gülmezoglu AM, Souza JP, Taneepanichskul S, Ruyan P, Attygalle DE, Shrestha N, Mori R, Nguyen DH, Hoang TB, Rathavy T, Chuyun K, Cheang K, Festin M, Udomprasertgul V, Germar MJ, Yanqiu G, Roy M, Carroli G, Ba-Thike K, Filatova E, Villar J, World Health Organization Global Survey on Maternal and Perinatal Health Research Group: Method of delivery and pregnancy outcomes in Asia: the WHO global survey on maternal and perinatal health 2007-08. Lancet 2010, 375:490-499.

27. Bogg L, Huang K, Long Q, Shen Y, Hemminki E: Dramatic increase of Cesarean deliveries in the midst of health reforms in rural China. Soc Sci Med 2010, 70:1544-1549.

28. Hsieh TT, Liou JD, Hsu JJ, Lo LM, Chen SF, Hung TH: Advanced maternal age and adverse perinatal outcomes in an Asian population. Eur J Obstet Gynecol Reprod Biol 2010, 148:21-26.

29. Fraser AM, Brockert JE, Ward RH: Association of young maternal age with adverse reproductive outcomes. N Engl J Med 1995, 332:1113-1117.
30. Chen XK, Wen SW, Fleming N, Demissie K, Rhoads GG, Walker M: Teenage pregnancy and adverse birth outcomes: a large population based retrospective cohort study. Int J Epidemiol 2007, 36:368-373.

31. Tough SC, Newburn-Cook C, Johnston DW, Svenson LW, Rose S, Belik J: Delayed childbearing and its impact on population rate changes in lower birth weight, multiple birth, and preterm delivery. Pediatrics 2002, 109:399-403.

32. Astolfi $\mathrm{P}$, Zonta LA: Risks of preterm delivery and association with maternal age, birth order, and fetal gender. Hum Reprod 1999, 14:2891-2894.

33. Cammu H, Martens G, Van Maele G, Amy JJ: The higher the educational level of the first-time mother, the lower the fetal and post-neonatal but not the neonatal mortality in Belgium (Flanders). Eur J Obstet Gynecol Reprod Biol 2010, 148:13-16.

\section{doi:10.1186/1471-2393-14-338}

Cite this article as: Sun et al:: Estimation of high risk pregnancy contributing to perinatal morbidity and mortality from a birth population-based regional survey in 2010 in China. BMC Pregnancy and Childbirth 2014 14:338.

\section{Submit your next manuscript to BioMed Central and take full advantage of:}

- Convenient online submission

- Thorough peer review

- No space constraints or color figure charges

- Immediate publication on acceptance

- Inclusion in PubMed, CAS, Scopus and Google Scholar

- Research which is freely available for redistribution 